\title{
Relationship between Citrus Productivity and Indicators of Uniformity in Trickle Irrigation System
}

\author{
João Carlos Cury Saad \\ Faculdade de Ciências Agronômicas, UNESP - Univ. Estadual Paulista \\ R. José Barbosa de Barros, 1780, 18610-307, Botucatu, SP, Brazil, joaosaad@fca.unesp.br
}

Hélio Moreira da Silva Júnior

Faculdade de Ciências Agronômicas, UNESP - Univ. Estadual Paulista

R.José Barbosa de Barros,1780. 18610-307,Botucatu, SP, Brazil, moreirahelio@hotmail.com

\author{
Written for presentation at the \\ 2012 ASABE Annual International Meeting \\ Sponsored by ASABE \\ Hilton Anatole \\ Dallas, Texas \\ July 29 - August 1, 2012
}

\begin{abstract}
In trickle irrigation systems, the design is based on the pre-established emission uniformity $(E U)$ which is the combined result of the equipment characteristics and its hydraulic configuration. However, this desired value of the EU may not be confirmed by the final project (in field conditions) and neither by the yield uniformity. The hypotheses of this research were: a) the EU of a trickle irrigation system at field conditions is equal to the emission uniformity pre-established in the its design; b) EU has always the lowest value when compared with other indicators of uniformity; c) the discharge variation coefficient (VC) is not equal to production variation coefficient in the operational unit; $d$ ) the difference between the discharge variation coefficient and the productivity variation coefficient depends on the water depth applied. This study aimed to evaluate the relationship between $E U$ used in the irrigation system design and the final yield uniformity. The uniformity indicators evaluated were: EU, distribution uniformity (UD) and the index proposed by Barragan \& Wu (2005). They were compared estimating the performance of a trickle irrigation system applied in a citrus orchard with dimensions of $400 \mathrm{~m} \times 600 \mathrm{~m}$. The design of the irrigation system was optimized by a Linear Programming model. The tree rows were leveled in the larger direction and the spacing adopted in the orchard was $7 \mathrm{~m} \times 4 \mathrm{~m}$. The manifold line was always operating on a slope condition. The sensitivity analysis involved different slopes, 0, 3, 6, 9 and 12\%, and different values of emission uniformity, 60, 70, 75, 80, 85, 90 and 94\%. The citrus yield uniformity was evaluated by the variation coefficient.
\end{abstract}

\footnotetext{
The authors are solely responsible for the content of this technical presentation. The technical presentation does not necessarily reflect the official position of the American Society of Agricultural and Biological Engineers (ASABE), and its printing and distribution does not constitute an endorsement of views which may be expressed. Technical presentations are not subject to the formal peer review process by ASABE editorial committees; therefore, they are not to be presented as refereed publications. Citation of this work should state that it is from an ASABE meeting paper. EXAMPLE: Author's Last Name, Initials. 2012. Title of Presentation. ASABE Paper No. 12----. St. Joseph, Mich.: ASABE. For information about securing permission to reprint or reproduce a technical presentation, please contact ASABE at rutter@asabe.org or 269-932-7004 (2950 Niles Road, St. Joseph, MI 49085-9659 USA).
} 
The emission uniformity (EU) after design differed from the EU pre-established, more sharply in the initial values lower than 90\%. Comparing the uniformity indexes, the EU always generated lower values when compared with the UD and with the index proposed by Barragan.

The emitter variation coefficient was always lower than the productivity variation coefficient. To obtain uniformity of production, it is necessary to consider the irrigation system uniformity and mainly the water depth to be applied.

Keywords. linear programming, irrigated citrus, trickle irrigation.

The authors are solely responsible for the content of this technical presentation. The technical presentation does not necessarily reflect the official position of the American Society of Agricultural and Biological Engineers (ASABE), and its printing and distribution does not constitute an endorsement of views which may be expressed. Technical presentations are not subject to the formal peer review process by ASABE editorial committees; therefore, they are not to be presented as refereed publications. Citation of this work should state that it is from an ASABE meeting paper. EXAMPLE: Author's Last Name, Initials. 2012. Title of Presentation. ASABE Paper No. 12----. St. Joseph, Mich.: ASABE. For information about securing permission to reprint or reproduce a technical presentation, please contact ASABE at rutter@asabe.org or 269-932-7004 (2950 Niles Road, St. Joseph, MI 49085-9659 USA). 


\section{Introduction}

In irrigation, uniformity is related to the ability of equipment to provide the same amount of water in the whole irrigated area. In drip irrigation systems, the design is based on the pre-established uniformity of emission (EU), which is the combination of the equipment characteristics and its hydraulic configuration (Keller \& Bliesner, 2000). However, this desired value of the EU may not be confirmed by the final project, due to the area slope and commercial pipe diameters, which rarely agrees exactly with those values defined in the design calculations.

Producers' goal is to have yield uniformity with quality. The fundamental question that motivated this research was if designing drip irrigation systems to obtain a high emission uniformity means getting also high yield uniformity.

The hypotheses of this research were: a) the EU of a trickle irrigation system at field conditions is equal to the emission uniformity pre-established in the its design; b) EU has always the lowest value when compared with other indicators of uniformity; c) the discharge variation coefficient (VC) is not equal to production variation coefficient in the operational unit; d) the difference between the discharge variation coefficient and the productivity variation coefficient depends on the water depth applied.

This study aimed to evaluate the relationship between the yield uniformity and irrigation uniformity on micro sprinkler irrigation system used in citrus.

\section{Methodology}

To verify the hypotheses, the following input variables combinations were considered:

a) pre-established emission uniformity: $60,70,75,80,85,90$ and $94 \%$;

b) slope in the manifold line direction: 0, 3, 6, 9 and 12\%;

c) Annual volumes applied of 3870,7740 e $11610 \mathrm{~L} /$ tree/year, corresponding to 30,60 e 90 days of irrigation per year.

To evaluate each combination involving pre-established emission uniformity and slope in the manifold line direction, a Linear Programming (LP) model of minimization cost was developed by Saad \& Marino (2002) and later modified by Marcussi et al. (2007). From the micro sprinkler irrigation system configuration, the LP model determined diameter combinations for each line of the hydraulic network in order to minimize the total cost. LP models were solved using the GAMS software, version 2.50 .

Comparative analysis was done using a hypothetical cultivated citrus area, with dimensions of $400 \mathrm{~m}$ by $600 \mathrm{~m}$ ( $24 \mathrm{ha}$ ) and slope in the shorter length direction $(400 \mathrm{~m})$. The planting rows were leveled in the larger direction $(600 \mathrm{~m})$. The tree spacing was $7 \mathrm{~m} \times 4 \mathrm{~m}$, with $4 \mathrm{~m}$ between trees in the row and $7 \mathrm{~m}$ between rows of plants, totaling $28 \mathrm{~m}^{2}$ per plant and 357 plants per ha. 


\section{Results and Discussion}

To verify if the pre-established EU match the EU obtained after the design with the commercial diameters, the optimization model was applied to 25 combinations, corresponding to five values of EU pre-established and 5 slopes (Table 1).

Seeing a lack of EU values lower than or equal to 80\%, for the slopes of 6, 9 and 12\%; the linear programming model indicated that there was no solution because occurred an overtake pressure variation in the operation unit, in which the limit was $80 \mathrm{~m}$ (pipeline pressure class - PN80). The use of a higher pressure class (PN125) would result in a higher cost of the project.

The final emission uniformity differed from the pre-established EU for all combinations that resulted in viable solutions. For the $90 \%$ pre-established $E U$, highly recommended in the literature, there was a variation of $-6.8 \%$ to $+2.3 \%$ between the final $\mathrm{EU}$ value and the preset value for the slope evaluated. The predefined EU of $94 \%$ showed variations between $+1.4 \%$ and $-8.2 \%$ for manifold line slopes from 0 to $12 \%$, respectively.

Table 1: Comparison between the pre-established EU and the final EU, for the 25 different combinations.

\begin{tabular}{|c|c|c|c|c|c|c|}
\hline \multirow{3}{*}{$\begin{array}{l}\text { Slope in the } \\
\text { manifold line } \\
\%\end{array}$} & \multicolumn{5}{|c|}{ Final Emission Uniformity (\%) } & \multirow{3}{*}{$\begin{array}{l}\text { Aver } \\
\text { age }\end{array}$} \\
\hline & \multicolumn{5}{|c|}{ Pre-established EU (\%) } & \\
\hline & 94 & 90 & 80 & 70 & 60 & \\
\hline & 95.31 & 92.07 & 88.36 & 84.59 & 82.25 & \\
\hline \multirow[t]{2}{*}{0} & $(+1.4 \%)^{1}$ & $(+2.3 \%)$ & $(+10.5 \%)$ & $(20.8 \%)$ & $(37.1 \%)$ & 88.5 \\
\hline & 91.91 & 88,79 & 85.93 & 84.24 & 83.83 & \\
\hline \multirow[t]{2}{*}{3} & $(-2.2 \%)$ & $(-1.3 \%)$ & $(7.4 \%)$ & $(20.3 \%)$ & $(39.7 \%)$ & 86.9 \\
\hline & 90.87 & 89.42 & & & & \\
\hline \multirow[t]{2}{*}{6} & $(-3.3 \%)$ & $(-0.6 \%)$ & - & - & - & 90.2 \\
\hline & 92.12 & 90.68 & & & & \\
\hline \multirow[t]{2}{*}{9} & $(-2 \%)$ & $(0.8 \%)$ & - & - & - & 91.4 \\
\hline & 86.27 & 83.88 & & & & \\
\hline 12 & $(-8.2 \%)$ & $(-6.8 \%)$ & - & - & - & 85.1 \\
\hline Average & 91.30 & 88.97 & 87.14 & 84.41 & 83.04 & 88.2 \\
\hline
\end{tabular}

${ }^{1}$ Variation between final EU and pre-established EU. 
Analyzing the level condition, it appears that the pre-established EU and the final EU are close with the values of 94 and 90\%. As the predefined EU decreases, starting from $90 \%$, the difference in relation to the final EU obtained increases. For example, for $0 \%$ slope in the manifold line, with a predefined EU of $80 \%$, it was obtained $88.36 \%$ at the end, with an increase of $10.5 \%$. This increase in uniformity is primarily associated to the optimized use of two diameters in the manifold line, only possible by design using a LP model.

The hypothesis that the final emission uniformity would be equal to the pre-established EU, it was not sustained in the condition level, the final EU values were always higher than the preestablished. In the others evaluated combinations, there was always a difference between the EU previous and final values.

In order to consider the effect of the water application efficiency in the yield uniformity, three applied volumes in cycle were evaluated, represented by 3h/day of irrigation during 30,60 and 90 days, which corresponds to 3870, 7740 and 11610 L/tree/year, respectively. The annual applied volume corresponding to 60 days of irrigation with $3 \mathrm{~h}$ per day of operation is the amount that allows for maximum yield, based on the water response function for citrus.

The 30 days application corresponds to water deficit and the 90 days application to an excessive amount (above the optimum), which can be seen in the water production function that is given by a polynomial equation of the second degree, with an initial increase stretch, an optimum range, and the a downside.

For the three volumes applied (Table 2) the production variation coefficient was always lower than the flow variation coefficient, for all EU combinations and slope studied. This indicates that there is an irrigation depth range that includes the yield maximum where the non-uniformity flow is eased by the water function response, which is a second degree polynomial.

Taking as an example the EU pre-established of $90 \%$ and the $3 \%$ slope in the manifold line direction, the flow variation coefficient for the operational unit was of $6 \%$. For the same combination of EU and slope, the yield variation coefficient for the excessive irrigation depth (11610 L/tree/yr) showed practically the same value of $5 \%$. For $3870 \mathrm{~L} / \mathrm{yr}$ the yield variation coefficient had a decreased of $2 \%$, which means three times lower, whereas for an optimum volume ( $7740 \mathrm{~L} / \mathrm{tree} / \mathrm{yr})$ the yield variation coefficient decreased to $0.19 \%, 30$ times smaller. This was repeated in almost all combinations tested, with minor values modification, but with the same trend. The first hypothesis related to this item states that "the VC flow does not match the VC production" is true, as shown above. Analyzing the VC production, it appears that there was a greater variation as a function of annual water volume applied than to the EU. 
Table 2: Flow and yield variation coefficients for slope different combinations, EU preestablished, and annual irrigation volume.

\begin{tabular}{|c|c|c|c|c|c|}
\hline \multirow{2}{*}{$\begin{array}{c}\text { EU Pre- } \\
\text { established } \\
(\%)\end{array}$} & \multirow{2}{*}{$\begin{array}{c}\text { Slope } \\
\% \\
\end{array}$} & \multirow[t]{2}{*}{$\begin{array}{c}\text { Flow } \\
\text { variation } \\
\text { coefficient }\end{array}$} & \multicolumn{3}{|c|}{ Yield variation coefficient } \\
\hline & & & $\begin{array}{c}3870 \\
\text { L/tree/yr }\end{array}$ & $\begin{array}{c}7740 \\
\text { L/tree/yr }\end{array}$ & $\begin{array}{c}11610 \\
\text { L/tree/yr }\end{array}$ \\
\hline \multirow{5}{*}{94} & 0 & 0.011 & 0.003 & 0.000 & 0.009 \\
\hline & 3 & 0.040 & 0.012 & 0.001 & 0.034 \\
\hline & 6 & 0.053 & 0.017 & 0.001 & 0.046 \\
\hline & 9 & 0.034 & 0.011 & 0.001 & 0.028 \\
\hline & 12 & 0.074 & 0.023 & 0.003 & 0.063 \\
\hline \multirow{5}{*}{90} & 0 & 0.034 & 0.011 & 0.001 & 0.029 \\
\hline & 3 & 0.063 & 0.020 & 0.002 & 0.054 \\
\hline & 6 & 0.058 & 0.018 & 0.002 & 0.050 \\
\hline & 9 & 0.040 & 0.013 & 0.001 & 0.034 \\
\hline & 12 & 0.086 & 0.027 & 0.004 & 0.072 \\
\hline \multirow{2}{*}{80} & 0 & 0.058 & 0.018 & 0.002 & 0.048 \\
\hline & 3 & 0.100 & 0.031 & 0.004 & 0.087 \\
\hline \multirow{2}{*}{70} & 0 & 0.095 & 0.030 & 0.004 & 0.082 \\
\hline & 3 & 0.124 & 0.038 & 0.006 & 0.103 \\
\hline \multirow{2}{*}{60} & 0 & 0.125 & 0.038 & 0.006 & 0.108 \\
\hline & 3 & 0.130 & 0.039 & 0.007 & 0.106 \\
\hline
\end{tabular}




\section{Conclusions}

According to obtained results and hypotheses, it is possible to conclude that:

a) the final EU was different from the EU pre-established and it was more sharply for values lower than $90 \%$; coefficient;

b) the operational unit flow variation coefficient was always greater than the yield variation

c) to obtain production uniformity, one must consider not only the irrigation system uniformity, but mainly selecting the appropriate water depth to be applied.

\section{Acknowledgements}

The authors thank CNPq - Conselho Nacional de Desenvolvimento Científico e Tecnológico for the financial support.

\section{References}

BARRAGAN, J.; WU, I. P. 2005. Simple pressure parameters for micro-irrigation design. Biosystems Engineering, London, v. 90, n. 4, p. 463-475.

KELLER, J.; BLIESNER, R. D. 2000. Sprinkle and trickle irrigation. Caldwell: The Blackburn Press. v. 1. 652 p.

MARCUSSI, F. F. N. ; SAAD, J. C. C. ; Souza, S. A. de ; Barreto, C. E. A. G. 2007. Análise da distribuição de carga hidráulica e vazão na unidade operacional de um sistema de irrigação localizada.. Irriga (Botucatu), v. 12, p. 481-491.

SAAD, J. C. C.; MARIÑO, M.A. 2002. Optimum design of microirrigation systems in sloping lands. Journal of Irrigation and Drainage Engineering (ASCE), Reston, VA, v. 128, n. 2, p. 116- 124. 